\title{
Interactive Contact as Linguistic Affordance during Short-Term Study Abroad: Myth or Reality?
}

\author{
Heather Allen \\ University of Miami
}

\section{Introduction}

The idea that study abroad (SA) is an ideal context for acquiring language is one largely supported by foreign language (FL) students and their teachers, the latter often recollecting their own successful if not life-transforming sojourns abroad (Kinginger, 2008). According to Rivers (1998), SA represents "an environment which most closely resembles the environment of the first language learner: continuously available target language input, in all possible modalities, registers, and domains" (p. 492). Yet despite potential benefits, students often do not take full advantage of learning opportunities during SA, instead spending time outside the classroom socializing with SA peers rather than trying to access social networks in the community that would most enhance FL learning (Freed, Segalowitz, \& Dewey, 2004; Miller \& Ginsberg, 1995; Wilkinson, 2000). In several cases, research has shown that host family members were the only native speakers with whom students had regular contact during SA (Kaplan, 1989; Tanaka, 2007). Further, at least two studies (Magnan \& Back, 2007; Rivers, 1998) comparing language gain by SA participants living in homestay families versus in residence halls contradicted the assumption that homestay contact results in superior linguistic outcomes. Mendelson (2004) concluded that most of SA participants' interactions outside the classroom in the FL were "limited spurts to fulfill very specific functions" with interlocutors such as bus drivers, store clerks, travel agents, and waiters (p. 51).

Even when SA participants engage in sustained interactions with native speakers outside the classroom, those interactions are not always as natural as one might believe since students have been shown to rely heavily on roles and norms of the classroom environment, attempting to cast interlocutors in a teacher-like role, a practice that is limiting if not inappropriate (Miller \& Ginsberg, 1995; Wilkinson, 2002). In addition, native speakers communicating with SA participants have been found to limit pragmatically appropriate language to be more readily understood (Iino, 2006; Siegal, 1995). 
Beyond research cited above pointing to a more nuanced view of student learning during SA, the "typical" SA experience for U.S. students today is not what it once was. Whereas the "Junior Year Abroad" model dominated by FL majors was once the norm, most SA participants are now specialists in social sciences, business and management, and humanities, with FL majors accounting for only seven percent of total enrollments (Institute for International Education, 2008; Kinginger, 2008). In addition, most students now participate in SA programs of less than eight weeks duration whereas less than five percent do so for an academic year (Institute for International Education). These trends toward shorter stays by non-FL majors call into question the motives informing why students choose to study abroad and assumptions about the inevitability of interactive contact and linguistic gain during SA.

Given previous research revealing SA participants' limited sustained interactions in the FL during SA, this study investigated interactive contact with French outside the classroom for 18 participants during short-term SA. In particular, this study sought to answer the following question: How much interactive contact with French (i.e., SA participant-homestay family members; SA participant-SA peers; SA participant-native speakers of French in the community) did SA participants report and to what degree was each form of contact perceived as a valuable affordance for FL learning?

Two notions motivated this study's focus. First, most SA research to date has concentrated on documenting linguistic outcomes, often comparing SA with at-home FL instruction, rather than investigating what students themselves do during SA to promote language learning. As Mendelson (2004) claimed, "Out of class contact, both interactive and noninteractive, is often lauded but rarely put to serious investigation" (p. 44). Second, as I have argued elsewhere (Allen, 2010; Allen, in press), successful classroom FL students do not necessarily become successful learners outside the classroom during SA, although the ways in which students learn to take an increasingly active role in language learning has been called "a relatively unexamined issue" (van Lier, 2008, p. 177). Thus, by delving into students' experiences interacting within the target language community and their perceptions regarding their transition from the FL classroom to SA, we can garner critical knowledge to inform the SA and undergraduate FL curricula. That is to say, insights related to both students' successful interaction strategies during SA as well as their difficulties in attempting to communicate with speakers of the target language should inform the content and goals of FL instruction before, during, and after SA. 


\section{Theoretical framework: \\ A sociocultural perspective on I anguage I earning}

Vygotskian cultural-historical psychology (Vygotsky, 1978), commonly called sociocultural theory in SLA research, is a theory of mind recognizing the critical role of social relationships and culturally constructed artifacts in organizing human thinking (Lantolf \& Thorne, 2006). Research informed by sociocultural theory focuses primarily on learners' participation in social interactions with others (rather than learning outcomes) as a means of becoming a participant in new discursive spaces (Pavlenko \& Lantolf, 2000). Mediation, a key concept in sociocultural theory, implies that humans' relationships to the world are established using physical and psychological tools, with language as the primary tool for directing and controlling behavior and relating to the world (Lantolf \& Appel, 1994).

It follows from this perspective that learning is first organized and regulated by more competent others (such as a parent or teacher) with the eventual goal that with appropriate collaboration and support, the learner will gain control, or selfregulation, and assume an agentic role in learning (Lantolf \& Appel, 1994). Such a view, described by van Lier (2008, p. 177) in specific relation to language learning as "the process of finding one's way in the linguistic world ... and taking an increasingly active role in developing one's constitutive role in it," foregrounds the notion of agency, or learners' contextually dependent initiative or responsibility for learning. Agency is seen not as a stable trait but a co-constructed phenomenon wherein individuals continually position themselves in relation to the learning process and learning environment (Lantolf \& Pavlenko, 2001). Moreover, according to Kinginger, "Access to language is shaped not only by learners' own intentions, but also by those of the others with whom they interact-people who may view learners as embodiments of identities shaped by gender, race, and social class" (2004, p. 221). Thus, the manifestation of a learner's agency is jointly dependent on the initiative of the learner and the reception of others in the learner's environment.

Whereas in many SLA theories and much research on negotiation, primacy is given to input transmitted to the learner in the learning environment, sociocultural theory privileges the notion of linguistic affordance, or a "particular property of the environment that is relevant ... to an active, perceiving organism in that environment ... [i]f the language learner is active and engaged, she will perceive linguistic affordances and use them for linguistic action" (van Lier, 2000, p. 252). The role of affordances picked up by the learner at that they promote his or her further action and lead to higher, more successful levels of interaction (Van Lier, 2004). Thus, emphasis is not placed solely on the learner 
or the environment but the relation between them. As such, the notions of linguistic affordance and learner agency are useful for investigating cognitive (internal) and contextual (external) aspects of FL learning, something particularly relevant to this study since language learning during SA has been called "highly unpredictable and serendipitous" (Wilkinson, 2005, p. 47).

\section{The study}

\section{Participants and the SA context}

Eighteen undergraduate students participated in this study. Among these, 17 spoke English as their first language and all were U.S. citizens. At the time of the study, 8 were intermediate-level French students (typically completing a French minor or International Business Certificate) who had completed two semesters of elementary-level French at their home institution prior to SA and 10 were majoring in French (often with a second major) and had already completed advancedlevel literature or cultural studies courses at the college level. The majority of participants (78 percent) had studied French in high school (on average for three years), including five of the intermediate-level participants and nine of the French Majors. The group included 12 women and 6 men whose average age was 20.4 years (See Appendix 1 for participants' background information.)

The six-week program took place during Summer 2006 in Nantes, a large city in Western France. The program was organized by the participants' home university, and students were taught by a U.S. faculty member and two nativespeaking university professors of French based in Nantes. Intermediate students completed three courses - in French language, culture and conversation, and creative writing. Advanced students also completed three courses-French art history, advanced culture and conversation, and creative writing. Per program rules, students were expected to use French to communicate during class, weekly cultural activities organized by the program assistant, and free time spent in the academic facility. Students lived with French homestay families (one per family) who provided a private bedroom and daily meals. The size of these families ranged from a single woman (three participants) to a couple (one participant) to a couple with one or two children at home (seven participants) and several couples with three or more children at home (seven participants).

\section{Research methods}

To investigate participants' experiences and perceptions related to interactive contact with French during SA, a mixed-methods design was used, including quantitative survey data and qualitative interview and learning blog data. By first 
analyzing data sources separately and later triangulating them, it was possible to document participants' perceptions and reported interactive contact, understand the meaning and significance of learning experiences from the participants' perspective, and interpret how their experiences and perceptions relate to how learner agency is enacted during SA and what types of interactive contact are most meaningful for SA participants.

Past SA research has revealed students' journals, travel logs, and diaries to be rich sources of data enabling a focus on personal studies of language learning (Kinginger, 2004). In this study, learning blogs completed twice weekly as a component of the writing course were the most comprehensive data source. Students were instructed to focus blog entries on FL and cultural learning, how and with whom time was spent outside class, and how their learning goals evolved. Blogging in French or English was acceptable since the rationale for blogging was not language practice but reflection ${ }^{1}$. In reality, seven of the eight intermediate-level participants' blogs were written in English whereas among advanced-level participants, four blogged in English, four in French, and two mixed English and French. Semi-structured interviews conducted in English, digitally recorded, and transcribed verbatim were another important data source, and participants were interviewed individually twice-a month before SA and during the program's final week.

Secondary data sources included surveys and e-mail correspondence between participants and the researcher in the year after SA. The internet-based surveys were completed a month before SA and during the program's final week. The pre-SA survey included a Language-Learning History and Language Contact Profile (adapted from Allen, 2002) whereas the post-SA survey included the Language Contact Profile plus Likert-type questions asking participants to assess their level of satisfaction with goal accomplishment and various forms of contact with French during SA.

Patterns and themes found in blogs and interviews were identified using inductive techniques (Strauss \& Corbin, 1990) and coded using a qualitative analysis program, QSR NVIVO. Once initial, unrelated coding categories were established, they were clustered into categories containing multiple subcategories, a recursive process that led to recoding data several times. Several strategies were used for verification of this study's analysis. Data was collected over a yearlong period including the six-week SA program, wherein the researcher interacted with participants multiple times weekly, facilitating the development of trust and engagement. Multiple data types were used to establish a confluence of evidence, and, conversely, the researcher searched for negative evidence by looking for 
disconfirming evidence to refine working hypotheses. Member checks took place as participants re-read their blogs, adding comments and clarifications, and later verified the accuracy of transcribed interviews.

Readers of this study should be aware that its findings are based on survey, interview, and blog data rather than the researcher's measurement of learning outcomes. Thus, findings illuminate how participants themselves perceive, represent, and interpret a short-term SA experience. However, generalizability of findings to other populations and settings, particularly for SA programs of different durations, may not be appropriate, and transferability of study implications should be interpreted by readers themselves.

\section{F i n d i n g s}

In the following pages, findings related to participants' reported interactive contact in French with host family members, SA peers, and other French speakers in Nantes as well as participants' perceptions of those forms of contact as linguistic affordances are synthesized. Appendix 2 presents a summary of participants' reported interactive contact in French.

\section{Homestay contact in French as linguistic affordance}

Among the three types of contact investigated, participants' interactions with homestay family members were reported as the most frequent and important form, despite variation in number of contact hours and perceptions of the family's role in learning. In fact, differences in participants' views emerged even before SA. The assumption that residing with a homestay family ensures SA participants of ongoing, sustained interaction in the FL was reflected in pre-SA comments of most participants. Characteristic of these students holding an idealistic view of homestay contact as a linguistic affordance were pre-SA comments from Kristen:

That will be the best way, because I am going to have to speak French, and that will make me really want to ... if I was going to live with other students in a dorm, it would be harder for me to try to make myself [speak French] ... it's exciting, I'm excited.

Evident in these remarks is the belief that living with a family would automatically compel Kristen to communicate in French and thus guarantee immersion and enhanced language abilities. In addition, Kristen, like several others, posited language acquisition as difficult if not impossible without a host family sojourn. 
Yet not every participant shared this outlook. Several viewed homestay as a potentially valuable affordance for learning language and/or culture and also a responsibility in terms of respecting family norms and expectations. For example, Abbie explained that homestay would "help me with a ton of my personal goals with French. And I guess they're going out of their way for me, so I can change somewhat for them. I'm just very independent and don't want to offend them." In addition, three students expressed reticence at the idea of living with a French family. Among these, Elise was "very worried" after a previous less-than-successful homestay sojourn in Spain yet wanted to try again. For Eric and Rachel, homestay simply did not draw them to SA — as Eric explained, "[I]f the program had offered a single-bedroom apartment for me to stay in, that wouldn't have changed my idea of going." Similarly, Rachel was uncertain that she wished to live with a family but said it might "feel a little more homey than living in a dorm."

Participants' remarks related to their goals for SA also revealed differences in perceptions of the homestay family role. When asked to list learning goals and later to explain how they envisioned pursuing them, the most common role stipulated for homestay contact was in learning about French culture (nine participants) or improving their French (six participants). More specifically, homestay contact was viewed as a way of experiencing French daily life, cultural comparisons, family dynamics, and political perspectives. Interestingly, all six participants who mentioned linguistic goals related them to orality (e.g., "forcing myself to talk," "further advancing my accent," "be comfortable speaking with a native speaker") rather than comprehension of spoken language or other linguistic elements. Finally, five participants explained social goals such as "get[ting] close with my family" or "build[ing] friendships / relationships with host family."

During SA, participants' reported daily homestay contact ranged from one to six hours, averaging 2.9 hours (see Appendix 2), with advanced-level students reporting 3.3 hours daily contact versus intermediate-level students reporting 2.5 hours of daily contact. According to participants, most contact occurred around dinnertime and activities outside the home were fairly limited-joining host family members at a cultural or sporting event, play, or movie was the most common activity, usually reported as occurring once (eight participants), followed by dining at another friend's or family member's home or in a restaurant (four participants), and running errands or attending religious services (three participants each).

Regardless of their incoming level of French, communication with the homestay family was an ongoing struggle to participate in conversations for many students. Typical of these experiences were the following blog entries: 
Anna: I find myself trapped in a world between childhood and adulthood, able to comprehend and converse with the children easily, but there's more difficulty with the adults. I can comprehend, I just can't always answer back. I think I'm yearning for a middle ground ...

Kathleen: Je suis très triste que je ne communique pas avec mes frères et mes parents plus facile. J'ai beaucoup pour parler mais c'est très dur. Quand j'ai parle de mon jour avec ma mere est facile mais le conversation comme entre les frères et les parents sont difficile pour moi être un partie du conversation.

[I am sad that I am not communicating with my brother and my parents more easily. I have a lot to say but it is very hard. When I talk about my day with my mom it is easy but conversation like between the brothers and the parents is hard for me to be a part of the conversation.]

Further, evening meals, the primary context for homestay interaction, were not always perceived as facilitating language use in the ways participants had previously imagined. Consider Rebecca's explanation of a meal with her hosts' extended family:

[I]n larger groups of people, I don't have as much confidence in adding things to conversations or making jokes ... they didn't have too many questions for me in that setting, so I spent a lovely 3.5 hour meal essentially as silent [Rebecca] ... I just haven't gotten to the comfort level yet where I can just randomly add to the conversation.

Another example of difficulty in negotiating communication was described by Natalie, who reflected on her family's attempt to teach her an expression for "I have had enough to eat":

[L]ast night I was trying to tell my mom and dad that I was full, and they gave me a phrase, something like "J'ai essayez," but without seeing it written down, I'm not sure exactly how it goes. They spelled it for me and I remember it ended in a z, but then it doesn't make sense because "essayer" is "to try" and using the passé compose it would make you say "I have tried," which I suppose could mean "I am full," but then why is the end of the word spelled with a $\mathrm{z}$ ? 
Natalie never realized that the word used was not essayer but assez; consequently, she failed to learn the idiomatic expression (J'en ai assez mangé) that her family introduced. She explained later that she could "only learn a word when I not only hear it but can look at it also."

In light of these communicative difficulties, host family members reacted in varying ways, with many taking on the role of teacher. For example, Abbie explained, "I told my mom the first day, 'Don't hesitate to correct me.' And it's funny when we talk, 'cause it's like every five seconds she corrects me, but it's great." Similarly, Claire described interactions with her homestay mother: "[E]lle simplement m'explique ce que les mots étrangers veulent dire. Construire mes propres phrases c'est la vraie difficulté ... Marie-Annick est miséricordieusement patiente. Elle attend pendant quelques longues secondes sans interrompre.» (She simply explains to me what foreign words mean. Constructing my own phrases is the real difficulty ... Marie-Annick is mercifully patient. She waits several long seconds without interrupting.) In total, 10 participants discussed host family members assuming a teacher-like role and using strategies of overt correction, explanations of French words or expressions, recasts of incorrect phrases, or slowing down speech, all viewed by participants as helpful and welcomed. Conversely, five participants described host family members not conforming to this role, resulting in disappointment or frustration. For instance, Chad wrote in his blog,

When my host family speaks to each other, I rarely understand the topic of conversation unless they take the time to work with me and explain what they're talking about. This happens often ... the family has many things to talk about when they all come home from school, work, etc., and little time to work with me.

Even at SA's end, Chad reported feeling "lost in the shuffle" since the family was "so busy with themselves." He, like others who expressed disappointment in a perceived lack of effort by host family members to help them linguistically, saw timing as problematic, since conversations typically took place around dinnertime and families had busy schedules and several children requiring attention.

One third of participants (six) reported communication breakdowns being resolved by host family members switching from French to English, a strategy perceived as useful by some and frustrating by others. Characteristic of those construing codeswitching as helpful was Natalie, who described typical communication with her host family as follows: 
When we aren't talking about basic pleasantries (food, the kids, our days, the weather, etc.) and we are talking about more important things, we use the fine art of Frenglish. Sometimes I improvise, I'll say a whole sentence in French, and then out of nowhere ... ENGLISH ... oops, but my mother and father do the same to me.

However, not all participants found this practice useful. As George explained,

Like yesterday, when [my host mother and I] were talking about how she got pulled over by the police for not letting someone merge and I didn't understand a word, so she explained it all in English. I was like, "I understand what you're saying, I just don't get this one word.” Her way of solving it is to say it all in English. Which I was like, "I understand English ... I'm not here for that."

A common theme for several participants was the discovery that interactive contact with their French family did not occur spontaneously but had to be nurtured. For example, Rebecca wrote,

Two nights ago I walked home with [Anna] and I was just really worked up and frustrated, mainly about life at "home" here ... I still can't make myself feel at ease. So I got home and felt awkward because the family seemed to be working on something in the kitchen, but it seemed as though I was interrupting. So I went to my room frustrated until dinner and then we ate.

[After dinner] I helped clean up and then it felt awkward again and so I felt defeated and was heading back up to my room. I decided I needed to be downstairs, so I brought postcards to write and my book to read and sat at the kitchen table hoping that could encourage some interaction. That ended up being a GREAT idea ... it allowed for conversation - actual conversationrather than the one phrase questions and responses.

Elise also reflected on how she had "forced herself to be in hard situations," such as a recent evening when her host mother invited friends to dinner, saying, "[From the moment people got there to the moment people left, I was down there. Regardless if I understood, if I was tired, I stayed there the whole time ... I've always made a really big effort to talk ... to be there." For these students, 
interacting in French with host family members was a struggle, yet they realized that maximizing contact was a choice, and, as a result, they maintained their motivation to communicate in French.

It would be misleading to suggest that all participants exercised agency accordingly. To the contrary, several simply changed focus when homestay communication broke down. For example, like Rebecca, Rachel could not seem to find adequate opportunities to interact with her host family, so, rather than seeking out new opportunities as did Rebecca, her evening routine evolved into the following, according to her blog: "After dinner, I go to my room and listen to music and read until I am ready to go to bed." Then, just a week later, Rachel wrote:

[My host family and I] have very little interaction and they seem content to keep it that way. I am no longer very optimistic that I will get to know my family better and that being around them will be any less awkward ...With the two weeks left in Nantes I want to do some more traveling. I am going to the beach and Mont St. Michel this weekend and Italy the weekend after that.

Like Rachel, Lindsay called homestay "probably the most awkward part of [SA]," explaining, "When I was home, I was usually trying to do my work but probably not much else ... I was busy. At first I felt a little bit abandoned, but then I had things to do and people to go out with if I wanted." For these students, life in the homestay family involved children's busy schedules and a lack of integration, resulting in a sense of demotivation to pursue linguistic goals. Common to these participants were blog discussions of time-consuming activities for homestay siblings (e.g., studying for the baccalauréat or competing in horse shows) causing the family to be preoccupied.

As was the case before SA, at its end, varying perceptions existed among participants as to the role of the homestay family. Descriptions included cultural, social, and linguistic roles, with some students focusing on one and others identifying two in response to the question "What role, if any, did your host family play in your SA experience?" Striking was the fact that less than half of participants (eight) focused their remarks on ways that living with a family had impacted their French language use, with slightly more (ten) concentrating on cultural aspects (e.g. "my family was more like the cultural things ... what a family does, what you eat, what you do on a day-to-day basis") and nine viewing the family as a source of social-psychological support or friendship ("it's been very helpful to have a mother and father figure here as a comfort thing”). As was the case before SA, orality was the continued focus of remarks by those students focusing on 
linguistic aspects, with more attention now shown to issues of register (and, in particular, "français familier") and pragmatic elements of language use.

In post-SA surveys, two thirds (12) of participants indicated that they were satisfied with homestay interaction in French. Those groups most satisfied were students who lived with a single woman, couple, or family with four or more children. The group of six participants in families with two to three adolescents and /or young adults was markedly less satisfied than others and both dissatisfied participants (Chad and Rachel) were in this group. Given the fact that most participants were satisfied with homestay contact in French, it was rather unsurprising that two thirds were "completely certain" or "very likely" to remain in contact with their host family after SA. However, contrary to these intentions, few participants remained in communication with them: Only Elise, Kathleen, and Molly continued exchanging emails or letters with a host family sibling and/ or mother in the year after SA.

In summary, it appeared that for the majority of participants, homestay contact in French during SA was an important affordance for cultural and/or language (primarily oral interaction) learning. Participants' comments suggested that to develop confidence for interacting in French in the homestay setting, it was necessary to overcome "awkwardness, frustration, and busy family schedules to capitalize on opportunities for communication, although dinnertime conversation, the main context for interaction, did not always afford opportunities for sustained discourse or negotiation of meaning. Finally, despite highly satisfying experiences interacting with homestay contact during SA for most participants, few sustained contact afterwards.

\section{Peer-to-peer contact in French as linguistic affordance}

As demonstrated in previous research, participants spent significant amounts of time with U.S. peers during SA, with reported daily contact outside coursework ranging from none to five hours, averaging 2.5 hours per participant. Intermediate- and advanced-level participants reported similar amounts of daily peer contact-averaging 2.3 versus 2.7 hours respectively. In comparison with time spent interacting with host families during SA (averaging 2.9 hours daily), eleven participants said they spent as much or more time with peers. In terms of the language used with peers outside class, on average, participants reported using French half the time, with four claiming to use French 75 percent of the time or more, nine using it half the time, and five using it 25 percent of the time (see Appendix 2). Somewhat predictably, advanced students claimed to use French more than intermediate students ( 55 versus 44 percent). 
Unlike interactive contact in French with homestay families, largely perceived as either a linguistic or cultural affordance (or both), participants' peer interactions in French generated more divided perceptions. Whereas eight participants viewed communicating in French with peers was helpful, ten believed it was not. Intermediate- and advanced-level participants were similar in terms of a divided view being observed within the two groups: For intermediate students, four out of eight ( 50 percent) viewed peer contact in French as an affordance; for advanced students, four out of ten ( 40 percent) viewed it as an affordance.

Thus, beyond certain cultural, psychological, and/or social benefits of their peers' presence (described by nearly all participants in blogs), in total, eight participants viewed interacting in French with U.S. peers as beneficial. Shared by these students was the idea that conversing casually or discussing questions related to learning French together represented a safe, comfortable context, (termed "the American safety net" by one participant), allowing them to build linguistic confidence. Eric, an intermediate student, explained the distinction between casual interactions with homestay family members versus his advanced peers, positing an advantage for the latter:

With my family, I like taking part in [conversations in French], but I just like to soak it in rather than ask questions and slow things down ... I like to give them the rhythm and sit back and listen to it. With the advanced students, it's much easier to have a conversation.

Also common to these students was the idea that certain individuals or a subgroup of peers were helpful in their linguistic efforts. Sam cited an advanced peer who was "a very helpful resource ... talking to him has improved my conversational French significantly," and Kristen, another intermediate student, claimed advanced peers "help me with things when I have questions. Sometimes I think it's easier to learn from someone the same age or at a closer level to you." Kathleen, an advanced student, also described the assistance of peers, saying they had "helped her a lot" with her oral French by offering corrections and volunteering vocabulary when she floundered. Another advanced student, Rebecca, explained in her blog how three peers (Adam, Anna, and George) supported her efforts to use French outside class:

J'apprends beaucoup de la langue et aussi jameliore dans la langue quand je la parle avec mes amis (quand je suis a l'aise). Aussi je pose beaucoup des questions et nous discutons quelque chose de la grammaire et la vocabulaire aussi. 
[I learn a lot of language and also I improve my language when I talk with my friends (when I am relaxed). Also I ask a lot of questions and we discuss things about grammar and vocabulary also.]

Rebecca elaborated on her blog comments in a follow-up interview, stating that in conversations with her host family, she had a tendency to "second guess myself and hesitate and then it doesn't make sense for me to say what i was going to say" whereas during interactions "with my friends and this kind of setting, it is a lot easier."

However, more than half of participants (eleven) felt that their American peers and, more specifically, the influence of the group more so than specific individuals in it, were disadvantageous for efforts to communicate in French. In participants' blogs, several issues emerged and perceptions explained which, taken together, clarify why the peer group was viewed as a constraint. The most widely discussed problem was a perception that despite the fact that participants were in a SA program in France, French was not the group's lingua franca. As Eric described it, "Whenever there are more than three or four people, English is let loose." Further, as Lindsay explained, "Whenever one person says anything at all in English, everyone in the conversation turns to English." A dual sense of disappointment and frustration with this situation was evident in a blog entry by Taylor:

NO ONE here speaks French. It's this ridiculous game-you speak in French, they respond in English. I guess I thought if we had "English time" every now and then when we got here, people wouldn't be overwhelmed so much by culture chock and we could acclimate. Instead "English time" has become progressively more prevalent.

This dynamic had a number of consequences on individual participants, including linguistic demotivation and anxiety that if a participant persevered in speaking French, it would result in rejection by peers. As Rebecca described it,

Quelquefois, les autres dans le grand group empêchent mes objectifs avec la langue, parce que souvent les gens parlent anglais et si je veux faire de la conversation avec eux, je me sens obligé de parler anglais aussi ... il y a un stigma je pense autour de l'idée de la langue-quelque chose qui crée la division et un peu des complexes d'infériorité et supériorité. 
[Sometimes, the others in the big group hinder my goals with (French), because often people speak English and if I want to make conversation with them, I feel obligated to speak English too ... there is a stigma I think around the idea of (French) - something that creates a division and a bit of inferiority and superiority complexes.]

Anna faced similar motivational challenges, writing, "I feel myself struggling to keep up the attitude to continue trying, especially when there are people who rarely speak a single word of French when we're not in class." In fact, when asked to identify her biggest challenge during SA, she replied, "The hardest and most frustrating part is dealing with everyone's different goals for being here. I guess I'm naïve, and I expect everyone else to have the same attitude and mentality I did."

In addition to the group's dominant use of English, a second problem developed-a spirit of competition that resulted in open criticism of certain students' French. As Kathleen explained, "The attitude that has started between people is distracting and annoying. It's nice to have the help and learn from one another but it's almost become a contest of who can speak the best French." Similarly, Molly described feeling as if more advanced peers were "frustrated" when interacting with intermediate students and "looked down on them." Her classmate Elise described a comparable opinion: "I feel that they are judging me based on my abilities (or lack thereof) ... I am slightly intimidated by them, but I am doing my best." In effect, this issue was also raised by two advanced students during interviews, Anna and Rebecca, with Anna openly admitting," [W] got in a rut with our group of friends of just being real critical of everyone else, like, 'Those people aren't speaking French!' or 'Did you hear what this person said?'” Evident in all these comments was the underlying reality that within the group, being an advanced student functioned as a sort of status marker, whereas some intermediate students felt demoralized by more advanced peers and anxious when speaking French with them, a phenomenon that those same students did not report in relation to other fluent French speakers.

To summarize, participants in this study spent on average as much or more time with peers than with homestay family members and French was not the dominant language for peer-to-peer interactions, although it was used to a considerable degree. Moreover, in comparison with interactions in French with homestay families, interactions in French within "the American safety net" were perceived to a lesser degree as a valuable linguistic affordance with more than half of participants viewing the U.S. peer group as a motivational constraint. 


\section{Contact with French speakers in the local community as linguistic affordance}

Although students and teachers might imagine SA participation leading naturally to spontaneous FL interactions beyond the classroom and formation of new relationships with local native speakers, participants in this study claimed to have had a different experience. With little exception, the only interlocutors with whom participants had repeated, sustained interactions in French were host family members and, in some cases, college-age friends of two participants' host family siblings (see Appendix 2). A common experience for participants was hesitation to initiate interactions in French with strangers, particularly young people. Thus, when participants were asked in a post-SA survey if they established contact with French people beyond their host family, seven responded that no such contact had occurred and six others said their only contact in French beyond service encounters was social outings with SA peers and young French friends of Molly's or Kathleen's homestay brothers. A shared perception among many participants was that French youth were not outgoing and thus unapproachable. Chad summarized this as "that's not how the French work, you don't usually just walk up to someone and start talking to them." As Natalie explained, "The young people here are a little more reserved than what we are used to in the U.S., so I didn't meet a lot [of them] ... it wasn't that I was going out and making friends." The five other participants described meeting French young people (who started conversations with the U.S. student, not vice-versa) in a bar, train, or at the beach during a one-time occasion, and for each, the contact was construed as valuable yet short-lived. Comments by Eric, an intermediate-level student, suggested that participation in such social interactions was challenging but rewarding:

$[\mathrm{A}] \mathrm{t}$ the bar last night there were several French kids that came over and started talking to $[\mathrm{Sam}]$ and I. And it was just interactions like that that were really, really interesting ...more towards the end I was willing to put myself in that situation whereas at the beginning, it would have been "Oh, jeez, no."

Rather than sustained conversations with French speakers in the community, chance encounters (i.e., providing directions to a stranger from another town) were described in several intermediate-level participants' blogs as quite motivating, providing a means of seeing the participant's progress in negotiating communication with strangers in French. Typical of these anecdotes was Sam's explanation of his efforts to pursue the goal to engage as actively as possible in French: 
A woman at my morning bus stop asked me if the bus had already gone by. Rather than simply telling her it hadn't, I explained to her that it was common for this bus to be between five and 10 minutes late because of the traffic ... She knew I wasn't exactly French, but that didn't matter ... I was proud of my ability to do it. These are the kinds of experiences I would like to have more of every day during these last two weeks.

Given the limited sustained interactions in French reported beyond the participants' homestay families, a somewhat surprising finding was that 10 participants were either satisfied or very satisfied with contacts formed in the local community, whereas just two, Claire and Rebecca, claimed to be dissatisfied (six said that they were neither satisfied nor dissatisfied). In addition, when asked at SA's end whether there were any things that they had tried to do unsuccessfully or whether they had any regrets about SA, only one participant (Claire) referred to interacting with locals. Among the four students stating they were "very satisfied" was Chad, who reflected on this aspect of SA and called it a "huge accomplishment": "It made me feel like I wasn't the fish in the fishbowl anymore-I was actually mingling with other French people and doing it well .... It's a great feeling to be able to fit in with the French crowd." However, not all participants were successful interacting with French people during SA. In a blog entry at the program's end, Claire explained regret that she had only formed one contacther host mother:

[L]es expériences de ce séjour sont formidable, mais mon seul lien à France est Marie-Annick. Je n’ai pas autres relations avec les Francais alors je n'ai pas pu profiter de mon séjour comme j'aurais souhaité ... the vrai culturel immersion que j’avais esperé pour n’est pas arrivé.

[The experiences from this stay are wonderful, but my only connection to France is Marie-Annick. I do not have other relationships with French people so I could not take advantage of my stay as I would have liked ... the real cultural immersion that I had hoped for did not happen.]

Therefore, in general, participants' interactive contact in French with people in the local community was limited, typically not extending beyond the circle of homestay families and consisting of casual social conversations with young people. Given the fact that nearly 40 percent of participants reported no interactive contact in French outside routine service encounters in the community, 
this contact was seen as a valuable linguistic affordance to a lesser degree than other forms of contact analyzed.

\section{Discussion}

This study's findings provide a detailed analysis of how much interactive contact with French participants in a short-term SA program report and to what degree contact with host family members, U.S. peers, and other French speakers in the local community are perceived as valuable affordances for FL learning. Whereas participants reported on average 2.9 hours of daily contact in French with host families and 1.3 hours with SA peers, interactions in French in the community beyond routine service encounters were infrequent and reported as occurring never for 39 percent of participants. In addition, in comparison with time spent interacting with host families, over 60 percent of participants said that they spent as much or more time with peers (2.5 hours on average). What little interactive contact participants had with locals typically occurred at bars or cafés as groups of U.S. students socialized on occasion with young French friends of two host families' college-age sons.

Thus, taken together, findings from this study support previous research demonstrating SA participants' lack of interaction in the community beyond the homestay family and tendency to create a "compatriot island" (Wilkinson, 2005) with peers rather than taking part in other social networks. Qualitative data from this study's participants sheds light on how students spend their time during SA and their perceptions of the linguistic environment of SA, findings which complement and help explain findings from outcome-focused investigations of language learning during short-term SA that have often revealed less dramatic language gain than anticipated by students. Further, this study's findings provide concrete examples of challenges encountered when SA participants attempt to participate in FL conversations (particularly mealtime ones) and negotiate communication, particularly in large host families. Evidence was also provided that interactive FL contact with host families was perceived by most participants as a valuable source of cultural and/or linguistic learning, albeit not always in the ways previously envisioned.

Findings related to amounts of reported interactive contact aside, the more interesting contribution of the present study may lie in what it reveals about how participants interacted outside the classroom during a typical SA sojourn and perceived various sources of FL contact. Within the SA group, not only did great variation exist among individuals - even those with the same incoming level of French-in terms of how much they interacted (or failed to interact) with 
host family members, peers, and others in the community, participants also held divergent perceptions of how others in the learning environment contributed to their language learning, and those perceptions, in turn, mediated their choices and behaviors related to interactions. For example, whereas some participants, like Elise, felt snubbed by peers and rejected opportunities to interact in French with them outside class while embracing opportunities for host family contact, others, like Rachel, did the opposite, having said even prior to SA that living with a host family was not of interest to her. While some participants, such as Claire, regretted the "American safety net" and her failure to make contacts in the host community beyond her host mother, others, such as Chad, found satisfaction in social interactions with young French people and felt that they contributed to not feeling like the "fish in the fishbowl" during SA. Moreover, whereas certain types of interactions such as dinnertime conversations with host family members represented a valuable affordance for enhancing some SA participants' linguistic abilities and language-learning motivation, for others, their inability to understand the conversations around them and their perceptions that their hosts were not making appropriate linguistic accommodations for them caused frustration. Thus, alongside certain general trends related to interactive contact in French for the group existed a multiplicity of individual experiences.

In terms of this study's theoretical implications, the diversity displayed in individual perceptions and experiences provides support for the notion, rooted in sociocultural theory, that learners are not simply processing devices converting linguistic input from the learning environment into output but agents who "actively engage in constructing the terms and conditions of their own learning" (Lantolf \& Pavlenko, 2001, p. 145). In fact, data from several participants demonstrate critical moments when a language learner was faced with a choice-to give a minimal utterance in the FL or provide a detailed response (e.g., Sam's bus stop encounter), to retreat to the safety of one's bedroom (e.g., Rachel) or to wait through times of awkwardness to encourage more interaction (e.g., Rebecca). In those key moments, we see agency enacted in ways that pushed certain learners' linguistic abilities and ultimately resulted in higher levels of interaction and sustained motivation. Data from this study also show diversity in learner agency in terms of how certain strategies or behaviors were maximized or avoided. For some participants, strategies such as code-switching were viewed as helpful, whereas for others, they were not; some participants pushed themselves to interact with French speakers in the community while others interacted only with peers or host family members, finding communicating with locals too stressful or difficult. 
It must also be noted that (although beyond this study's focus) the reasons why learners construct learning as they do are anchored not only in their interactions with and perceptions of the learning environment but also in their social histories, language-learning motives and goals, and future academic or professional aspirations (see Allen, 2010, for a related discussion). A perusal of participants' reasons for choosing to SA (see Table 1) reveals much diversity within the group as well as the fact that several claimed to have participated in SA to excel progress toward meeting academic requirements. Indeed, two of those students (Chad and Rachel) were among the participants who were least satisfied with homestay contact while simultaneously reporting a majority of peer interactions in English.

In addition, this study's findings contradict an assumption implicit in much SA research - that the SA context as a learning environment naturally generates language learning for students, who simply absorb language from native speakers around them like sponges. Instead, this research presents evidence to support a relational definition of $\mathrm{SA}$ as a learning context emerging from the dynamic interplay between the learner's intentions versus those in his or her community of practice. A number of elements mediate how language learning and learners' motivation to continue using the FL evolve during SA-both internal (e.g.., language-learning motives and goals, beliefs related to the FL and host culture, personality factors, capacity for risk-taking, perceptions of the linguistic environment) and external (e.g., reception by host family members and others in the community, relations with peers). Further, the conception of motivation supported by this study as based partly on how the language learner interacts with the surrounding social environment is consistent with other researchers' (Dörnyei, 2009; Kim, 2009; Ushioda, 2007) recent assertions that motivation is not a stable trait but is situation-dependent and varies over time.

Finally, findings from this study have a number of practical implications for SA participants, faculty, and program administrators. Although, on one hand, these findings challenge the idealistic yet widespread notions that interactive FL contact and the formation of lasting relationships in the host community is inevitable during SA, on the other hand, they provide clear examples of productive learning behaviors that resulted in satisfying linguistic interactions and SA sojourns. Such examples should be discussed with students as part of pre-program orientation to linguistic and cultural challenges of SA along with candid information on what realistic expectations for short-term SA should be. Perhaps if students were explicitly told that establishing friends with French youth their age was more the exception than the rule, they could be challenged to find specific contexts in which such interactions could be nurtured; likewise, if students 
were aware that homestay contact does not flourish organically but must be nurtured actively, they could better prepare for the difficult transition of living with a host family. Further, given the variation among SA participants' perceptions and experiences in this study, programs would be well advised to gather data (e.g., questionnaires and interviews) from future SA participants and have faculty meet with individual students to discuss strategies for maximizing interactive contact given the individual's linguistic and cultural interests and goals. Moreover, the fact that participants in this study reported difficulty in initiating conversations and finding topics for discussion with interlocutors suggests an over-reliance on classroom discourse norms wherein the teacher controls the interactions and students are relegated a more passive role. Addressing this phenomenon would require concerted effort by FL faculty at all levels of the FL curriculum to create and carefully structure activities and tasks to increase student initiative in classroom interactions and other language-learning activities.

\section{Conclusion}

Findings from this study offer insights into the benefits of participating in short-term SA and the limitations of SA participants' contact with the host community. Although, as Wilkinson (2002, p. 169) noted, "Perhaps immersion in a target-language community does not always take students as far beyond the classroom as one might intuitively believe," it remains the task of researchers to continue investigating why this is the case and how the FL curriculum can best support efforts to maximize language learning before, during, and after SA.

\section{Note}

${ }^{1}$ Participants' blog entries are cited as they were posted online. Errors of spelling and grammar in French have not been corrected. However, when referring to other participants, pseudonyms have been inserted.

\section{References}

Allen, H. W. (2010). "Language-learning motivation in short-term study abroad." Foreign Language Annals 43, 27-49.

Allen, H.W.(2002). Does study abroad make a difference? A study of motivational and linguistic outcomes (Doctoral dissertation, Emory University, 2002). Dissertation Abstracts International, 63, 1279.

Allen, H. W. (in press). "What shapes short-term study abroad experiences? A comparative case study of students' motives and goals." Journal of Studies in International Education. 
Dörnyei, Z. (2009). Individual differences: Interplay of learner characteristics and the learning environment. Language Learning 59, 230-248.

Freed, B. F., Segalowitz, N., \& Dewey, D. P. (2004). Context of learning and second language fluency in French. Studies in Second Language Acquisition, 26, 275-311.

Ino, M. (2006). Norms of interaction in a Japanese homestay setting: Toward two-way flow of linguistic and cultural resources. In M. A. DuFon \& E. Churchill (Eds.), Language learners in study abroad contexts (pp. 151173). Clevedon, UK: Multilingual Matters.

Institute of International Education. (2008). Open doors: Report on international educational exchange. Retrieved July 1, 2009, from http://opendoors. iienetwork.org/

Kaplan, M. A. (1989). French in the community: A survey of language use abroad. The French Review, 63, 290-299.

Kim, T-Y. (2009). The dynamics of L2 self and L2 learning motivation: A qualitative case study of Korean ESL students. English Teaching, 64 (3), 49-70.

Kinginger, C. (2004). Alice doesn't live here anymore: Foreign language learning and identity reconstruction. In A. Pavlenko \& A. Blackledge (Eds.), Negotiation of Identities in Multilingual Contexts (pp. 219-242). Clevedon, UK: Multilingual Matters.

Kinginger, C. (2008). Language learning in study abroad: Case histories of Americans in France. Modern Language Journal Monograph Series, Volume 1. Oxford: Blackwell.

Lantolf, J. P. \& Appel, G. (1994). Theoretical framework: An introduction to Vygotskian approaches to second language research. In J. P. Lantolf \& G. Appel (Eds.), Vygotskian approaches to second language acquisition (pp. 128). Norwood, NJ: Ablex.

Lantolf, J. P. \& Pavlenko, A. (2001). (S)econd (L)anguage (A)ctivity theory: Understanding second language learners as people. In M. Breen (Ed.), Learner Contributions to Language Learning: New Directions in Research (pp. 141-158). London: Longman.

Lantolf, J. P., \& Thorne, S. L. (2006). Sociocultural theory and the genesis of second language development. Oxford: Oxford University Press.

Magnan, S. S., \& Back, M. (2007). Social interaction and linguistic gain during study abroad. Foreign Language Annals, 40, 43-61.

Mendelson, V. G. (2004). “Hindsight is 20/20:” Student perceptions of language learning and the study abroad experience. Frontiers: The Interdisciplinary Journal of Study Abroad, 10, 43-63. 
Miller, L., \& Ginsberg, R. B. (1995). Folk linguistic theories of language learning. In B. F. Freed (Ed.), Second language acquisition in a study abroad context (pp. 294-315). Amsterdam: Benjamins.

Pavlenko, A. \& Lantolf, J. P. (2000). Second language learning as participation and the (re)construction of selves. In J. P. Lantolf (Ed.), Sociocultural Theory and Second Language Learning (pp. 155-177). Oxford: Oxford University Press. Rivers, W. P. (1998). Is being there enough? The effects of homestay placements on language gain during study abroad. Foreign Language Annals, 31, 492-500.

Siegal, M. (1995). Individual differences and study abroad: Women learning Japanese in Japan. In B. F. Freed (Ed.), Second Language Acquisition in a Second Abroad Context (pp. 225-243). Philadelphia: John Benjamins.

Strauss, A., \& Corbin, J. (1990). Basics of qualitative research: Grounded theory procedures and techniques. Newbury Park, CA: Sage.

Tanaka, K. (2007). Japanese students' contact with English outside the classroom during study abroad. New Zealand Studies in Applied Linguistics, 13, 36-54.

Ushioda, E. (2007). Motivation, autonomy and sociocultural theory. In D. Little, J. Ridley and E. Ushioda (Eds.), Learner Autonomy in the Foreign Language Classroom: Teacher, Learner, Curriculum and Assessment (pp. 5-24). Dublin: van Lier, L. (2008). Agency in the classroom. In J. P. Lantolf and M. E. Poehner (Eds.), Sociocultural theory and the teaching of second languages (pp. 163186). London: Equinox.

van Lier, L. (2004). The ecology and semiotics of language learning: A sociocultural perspective. Boston: Kluwer Academic Publishers.

van Lier, L. (2000). From input to affordance: Social-interactive learning from an ecological perspective. In J. P. Lantolf (Ed.), Sociocultural theory and second language learning (pp. 245-259). Oxford: Oxford UP.

Vygotsky, L. S. (1978). Mind in society: The development of higher psychological processes. Cambridge: Harvard University Press.

Wilkinson, S. (2005). Articulating study abroad: The depth dimension. In C. M. Barrette and K. Paesani (Eds.), Language program articulation: Developing a theoretical foundation. Issues in language program direction: A series of annual volumes (pp. 44-58). Boston: Heinle.

Wilkinson, S. (2002). The omnipresent classroom during study abroad: American students in conversation with their French hosts. Modern Language Journal, 86, 157-173.

Wilkinson, S. (2000). Emerging questions about study abroad. ADFL Bulletin, $32(1), 36-41$. 


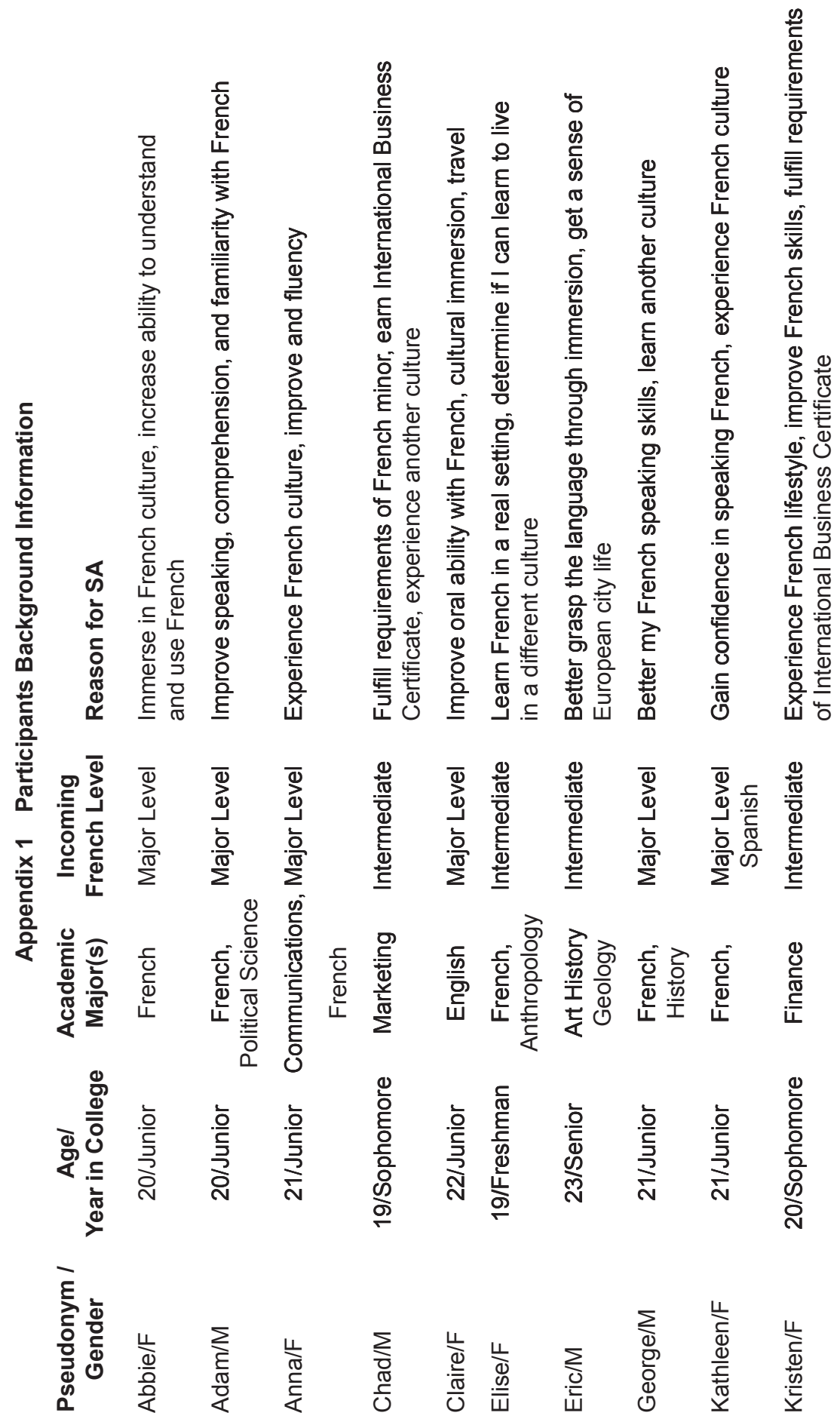




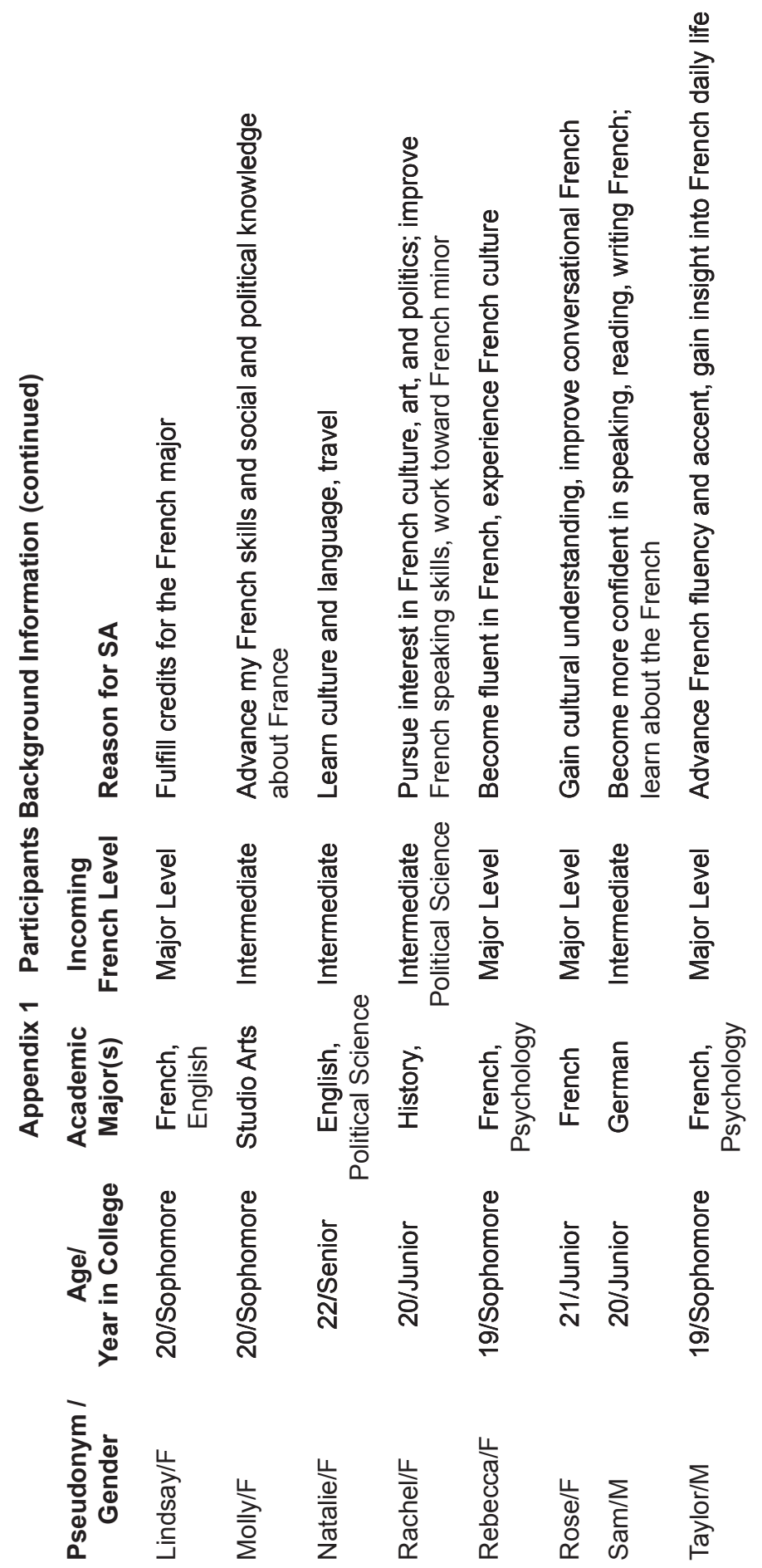




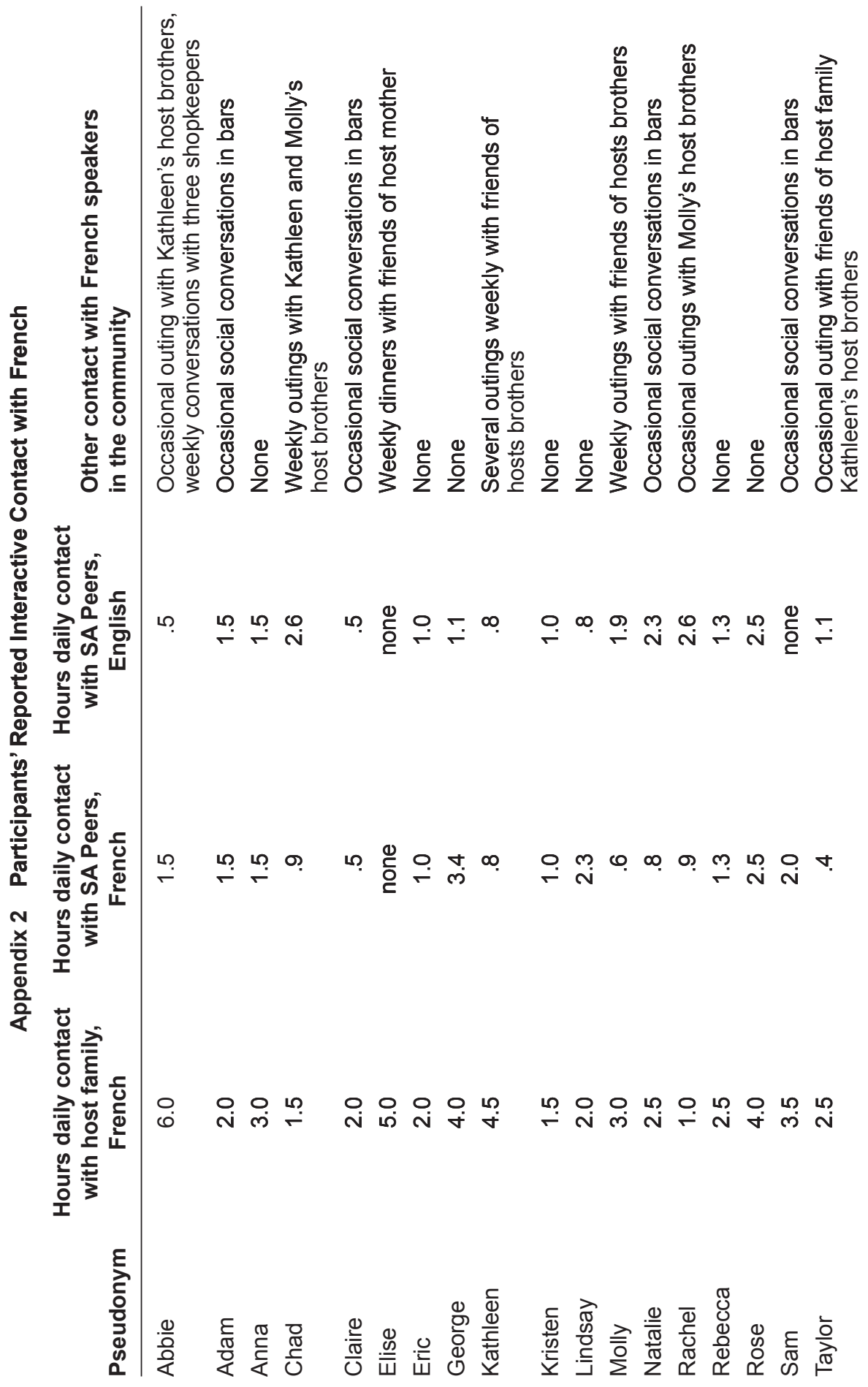

